\title{
Ispit iz matematike na državnoj maturi post festum
}

\author{
Vinko Bajrović
}

\section{Sažetak}

Iznošenje argumenata koji ukazuju na potrebu ukidanja ispita iz matematike na osnovnoj razini koji se rješava na državnoj maturi. S maturantima se u 12 godina obrazovanja ostvaruje 1120 sati nastave matematike u osnovnoj školi i 420 ili 560 sati u srednjoj školi (ovisno odnose li se sati na 3 ili 4 sata nastave matematike tjedno), dakle ukupno 1540 ili 1680 sati nastave matematike. Nema potrebe da se elementarnim zadatcima, većinom iz programa matematike osnovne škole, ispituje znanje maturanata. Predlaže se jedinstveni ispit matematike na državnoj maturi.

Posebno se ukazuje na problem ocjenjivanja ispita iz matematike na državnoj maturi, niske pragove za pojedinu ocjenu (odstupanje od normalne raspodjele). Predlaže se uz ocjenu i evidentiranje postotne rješivosti zadataka. Zabrinjavajuće su ocjene učenika na ispitu iz matematike ostvarene na državnoj maturi školske godine 2017./2018. u ljetnom roku.

Ključni pojmovi: državna matura, ispit iz matematike na osnovnoj razini, jedinstveni ispit, pragovi za pojedine ocjene i postotna rješivost zadataka, prijedlozi.

\section{Eliminirati na državnoj maturi ispite iz matematike na osnovnoj razini}

Višekratno upozoravam da ispite osnovne razine na državnoj maturi treba eliminirati. Zašto? Zato jer su sramota za učenike koji, na primjer, 
nisu u stanju ostvariti pozitivnu ocjenu iz matematike na poznavanju temeljnog gradiva iz programa osnovne škole. Je li ikome uopće neugodno za negativne ocjene iz matematike ostvarene na ispitu iz matematike na osnovnoj razini? Učiteljima osnovne škole? Nastavnicima u srednjoj školi? Učenicima? Onima čiji su ,projekt” ispiti osnovne razine?

Netko se „poigrao” i želio omogućiti, posebno učenicima sa završenom strukovnom školom, bez obzira na tjedni, odnosno godišnji broj sati nastave matematike, koji su već stekli svoje prvo zvanje, da se polaganjem, uglavnom ispita državne mature na osnovnoj razini, „domognu” uvjeta za upis na fakultet. To je osnovni razlog za veliki broj ostvarenih negativnih ocjena. Mnogi učenici, posebno strukovnih škola, nepripremljeni ili vrlo slabo pripremljeni dolaze polagati ispit iz matematike s filozofijom „idem pokušati, nemam što izgubiti”. 19707 učenika strukovnih škola polagali su ispit iz matematike na državnoj maturi (ljetni rok 2018.) i "zaradili" 3146 negativne ocjene.

Što treba napraviti u smislu unapređivanja sustava državne mature? Ponavljam, eliminirati ispite iz matematike na osnovnoj razini! Ispite provoditi samo na jednoj razini, jedinstven ispit, a među zadatke te jedinstvene razine inkorporirati dio jednostavnijih zadatka za učenike skromnijeg znanja, ali ne banalizirati i tu "skromnost".

Učenici su u osnovnoj školi imali 4 sata matematike tjedno, odnosno 140 sati godišnje ili kroz osnovnu školu $140 \times 8=1120$ (sati). Ako se $k$ tomu doda još 140 sati matematike u prve dvije godine (četverogodišnje strukovne škole koje imaju po dva sata tjedno ili 70 sati) ili 560 sati matematike (četverogodišnje strukovne škole koje imaju četiri sata tjedno ili 140 sati godišnje), tada se može kazati da su učenici kroz osnovnu $i$ srednju školu imali od 1120 sati $(O \check{S})+140$ sati $(S \check{S})=1260$ sati do 1120 $(O \breve{S})+560(S \breve{S})=1680$ sati. Nameće se, stoga, pitanje jesu li mogli nakon toliko sati nastave matematike, za pozitivnu ocjenu riješiti zadatke osnovne razine na ovogodišnjoj državnoj maturi (ljetni rok 2018.) koji slijede.

\section{Zadatci osnovne razine na ovogodišnjoj državnoj maturi}

Ovdje će se navesti dio zadataka od njih 40 koje se moglo s lakoćom riješiti za ostvarenje pozitivne ocjene (zadatcima je prirodnim brojem označen redni broj iz originalnog pismenog ispita, a rimskim brojem program razreda osnovne škole):

1.-VI. Koja je od navedenih nejednakosti točna? 

A. $\frac{5}{7}<\frac{4}{9}$
B. $\frac{5}{7}<0.5$
C. $\frac{5}{7}>\frac{10}{11}$
D. $\frac{5}{7}>0.7$

2.-V. Ana je stigla na stanicu u 7:42 sati i čekala vlak. Njezin vlak, koji je trebao stići u 8:05 sati kasnio je 12 minuta. Koliko je dugo Ana čekala vlak?
A. 31 minutu
B. 34 minute
C. 35 minuta
D. 38 minuta

5.-V. Kolika je razlika najvećega i najmanjega dvoznamenkastog broja koji su djeljivi s brojem 5 ?
A. 80
B. 85
C. 90
D. 95

6.-VII. Umnožak dvaju pozitivnih brojeva je 640 . Koliki je njihov zbroj ako im je omjer $2: 5$ ?
A. 42
B. 48
C. 56
D. 64

7.-VII. Podatci o visini i broju učenika nekoga razreda navedeni su $u$ tablici.

\begin{tabular}{|c|c|}
\hline Visina & Broj učenika \\
\hline \hline $172 \mathrm{~cm}$ & 5 \\
\hline $176 \mathrm{~cm}$ & 3 \\
\hline $178 \mathrm{~cm}$ & 10 \\
\hline
\end{tabular}

Nakon što su u taj razred upisna još 2 učenika iste visine, prosječna visina učenika u tome razredu je $177 \mathrm{~cm}$. Kolika je visina novoupisanih učenika?
A. $177 \mathrm{~cm}$
B. $180 \mathrm{~cm}$
C. $183 \mathrm{~cm}$
D. $186 \mathrm{~cm}$

8.-VII. Majica košta $85 \mathrm{kn}$, a hlače $199 \mathrm{kn}$. U petak je cijena majice snižena $10 \%$, a cijena hlača $25 \%$. Koliko će se posto uštedjeti kupovinom obaju artikala toga petka?
A. $15 \%$
B. $17.51 \%$
C. $20.51 \%$
D. $35 \%$

9.-VIII. Mreža kojega geometrijskoga tijela je prikazana na skici?

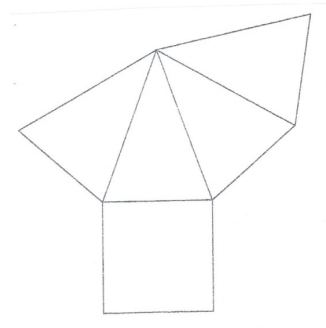
A. četverostrana prizma
B. četverostrana piramida
C. trostrana prizma
D. trostrana piramida 
10.-VIII. U prazan akvarij koji ima oblik kvadra duljine $50 \mathrm{~cm}$, širine $30 \mathrm{~cm}$ i visine $40 \mathrm{~cm}$ uliveno je 18 litara vode. Do koje je visine voda ispunila akvarij? Napomena: $1 \mathrm{~L}=1 \mathrm{dm}^{3}$.
A. do $12 \mathrm{~cm}$
B. do $14 \mathrm{~cm}$
C. do $18 \mathrm{~cm}$
D. do $20 \mathrm{~cm}$

11.-VIII. Brod je isplovio iz luke. Najprije je 2 sata plovio prema istoku brzinom $12 \mathrm{~km} / \mathrm{h}$, a onda je okrenuo prema sjeveru i 5 sati plovio brzinom $14 \mathrm{~km} / \mathrm{h}$. Koliko je nakon tih sati plovidbe bio udaljen od luke?
A. $69 \mathrm{~km}$
B. $74 \mathrm{~km}$
C. $79 \mathrm{~km}$
D. $84 \mathrm{~km}$

12.-VII. Na skici su prikazana tri kruga s promjerima $\overline{A B}, \overline{B C}$ i $\overline{A C}$. Duljina promjera $\overline{A B}$ je $12 \mathrm{~cm}$, a promjera $\overline{B C}$ je $8 \mathrm{~cm}$. Kolika je površina osjenčanoga dijela na slici?

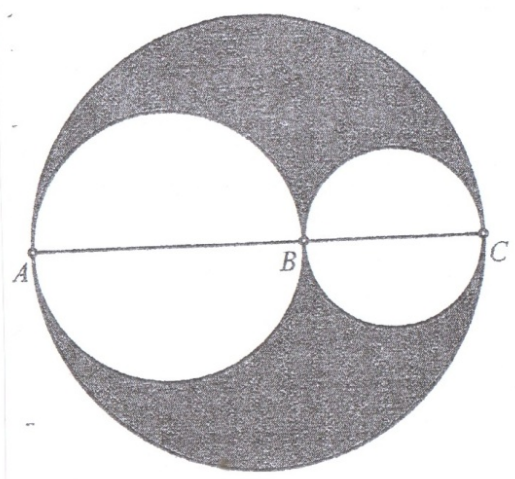
A. $18 \pi \mathrm{cm}^{2}$
B. $20 \pi \mathrm{cm}^{2}$
C. $34 \pi \mathrm{cm}^{2}$
D. $48 \pi c m^{2}$

15.-V. Na zagrebačkome maratonu 2015g்odine sudjelovalo je 317 maratonaca koji su istrčali stazu duljine 42.195 km i 1307 polumaratonaca koji su istrčali stazu duljine $21.097 \mathrm{~km}$. Ako zbrojimo kilometre koje su istrčali svi maratonci i kilometre koje su istrčali svi polumaratonci te ih usporedimo, koja je od navedenih tvrdnja točna?

A. Maratonci su istrčali ukupno 14197.964 km manje od polumaratonaca.

B. Maratonci su istrčali ukupno $20886.03 \mathrm{~km}$ manje od polumaratonca.

C. Maratonci su istrčali ukupno 14197.964 km više od polumaratonaca.

D. Maratonci su istrčali ukupno $20886.03 \mathrm{~km}$ više od polumaratonaca. 
10 od ovih 11 zadataka (zadatci višestrukog izbora - ponuđena četiri odgovora) je trebalo za 150 minuta riješiti za pozitivnu ocjenu. Ako bi se $\mathrm{k}$ tome dodali i neki od ostalih zadataka:

19.2.-VII. Od kojega broja $0.35 \%$ iznosi 1.96 ?

20.1.-VII. Riješite jednadžbu $\frac{7}{x-4}=\frac{7}{3 x}$.

21.1.-VI. Odredite broj koji je za 172 manji od trostruke vrijednosti toga broja.

21.2.-VI. U košari je 48 komada voća (jabuke, kruške, limuni). Pet osmina su jabuke, a trećina ostaloga voća su kruške. Koliko je komada limuna u košari?

22.1.-VII. Izrazite $b$ iz formule $a=\frac{2 c}{b}+3$.

23.1.-VII. Riješite sustav jednadžba $3 y=9-2 x$ i $4 x-8=5 y-1$.

24.1.-VIII. Koliki je opseg četverokuta ABCD prikazanoga na skici?

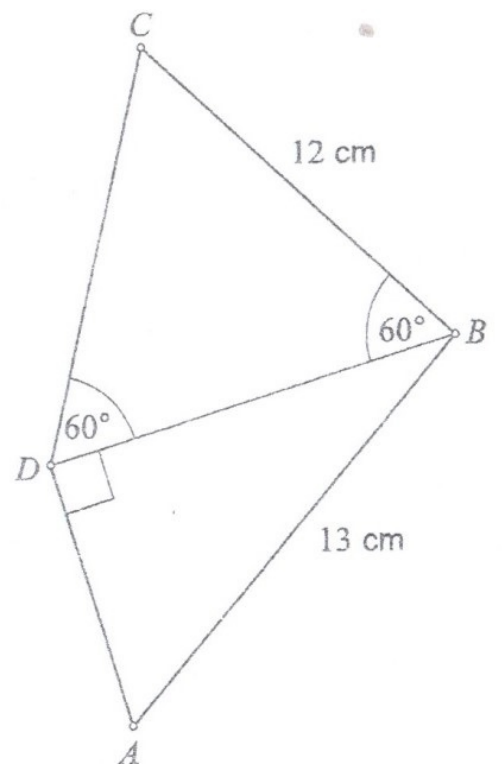

24.2.-V. Odredite mjeru kuta $\alpha$ prikazanoga na skici. 


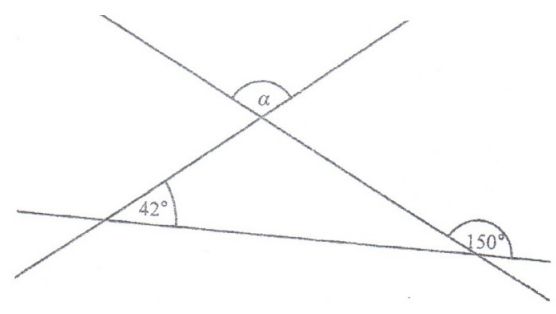

Učenik koji bi od ovih 19 zadataka riješio njih 10, dobio bi prolaznu ocjenu (dovoljan), a onaj koji bi riješio svih 19, dobio bi ocjenu dobar. Smiješan maturalni ispit, nakon 1260, odnosno 1680 sati nastave matematike prije dolaska na ispit državne mature, zar ne? Neka bude dozvoljeno naglasiti, ako nakon 1540 nastave u osnovnoj školi i još 140, odnosno 560 sati nastave matematike u srednjoj školi nije u stanju riješiti ove zadatke, onda ovaj zapis ozbiljno upozorava na kvalitetu nastave, rad učenika, sustav ocjenjivanja i nužnost reforme školstva.

\section{Postotna rješivost zadataka i bodovni in- tervali}

Ovdje će se predstaviti dvije tablice pragova, odnosno postotne rješivosti zadataka iz matematike na državnoj maturi zadnjih pet godina provođenja državne mature na osnovnoj i višoj razini, odakle proizlaze ocjene. Treba uočiti vrlo nizak prag prolaznosti za pozitivnu ocjenu, znatno odstupanje od normalne raspodjele i što je vrlo bitno veliku postotnu razliku za ostvarenje pojedine ocjene.

\begin{tabular}{|c||c|c|c|c|c|}
\hline Ocjene & $2013 . / 2014$. & $2014 . / 2015$. & $2015 . / 2016$. & $2016 . / 2017$. & $2017 . / 2018$. \\
\hline \hline 1 & $0.00-24.99$ & $0.00-24.99$ & $0.00-24.99$ & $0.00-23.99$ & $0.00-24.99$ \\
\hline \multirow{2}{*}{2} & $25.00-49.99$ & $25.00-49.99$ & $25.00-49.99$ & $24.00-46.99$ & $25.00-46.99$ \\
& $(24.99)$ & $(24.99)$ & $(24.99)$ & $(22.99)$ & $(21.99)$ \\
\hline \multirow{2}{*}{3} & $50.00-72.99$ & $50.00-69.99$ & $50.00-69.99$ & $47.00-66.99$ & $47.00-66.99$ \\
& $(22.49)$ & $(19.99)$ & $(19.99)$ & $(19.99)$ & $(19.99)$ \\
\hline \multirow{2}{*}{4} & $72.50-89.99$ & $70.00-86.99$ & $70.00-86.99$ & $67.00-84.99$ & $67.00-84.99$ \\
& $(17.49)$ & $(16.99)$ & $(16.99)$ & $(17.99)$ & $(17.99)$ \\
\hline \multirow{2}{*}{5} & $90.00-100.00$ & $87.00-100.00$ & $87.00-100.00$ & $85.00-100.00$ & $85.00-100.00$ \\
& $(10.00)$ & $(13.00)$ & $(13.00)$ & $(15.00)$ & $(15.00)$ \\
\hline
\end{tabular}

Tablica 1: Osnovna razina (ljetni rok) - postotna rješivost. U zagradama je naznačena razlika za istu ocjenu. 


\begin{tabular}{|c||c|c|c|c|c|}
\hline Ocjene & $2013 . / 2014$. & $2014 . / 2015$. & $2015 . / 2016$. & $2016 . / 2017$. & $2017 . / 2018$. \\
\hline \hline 1 & $0.00-28.32$ & $0.00-27.99$ & $0.00-27.99$ & $0.00-24.99$ & $0.00-24.99$ \\
\hline \multirow{2}{*}{2} & $28.33-49.99$ & $28.00-49.99$ & $28.00-49.00$ & $25.00-45.99$ & $25.00-45.99$ \\
& $(21.66)$ & $(21.99)$ & $(21.99)$ & $(20.99)$ & $(20.99)$ \\
\hline \multirow{2}{*}{3} & $50.00-74.99$ & $50.00-69.99$ & $50.00-69.99$ & $46.00-65.99$ & $46.00-67.99$ \\
& $(24.99)$ & $(19.99)$ & $(19.99)$ & $(19.99)$ & $(21.99)$ \\
\hline \multirow{2}{*}{4} & $75.00-89.99$ & $70.00-82.99$ & $70.00-82.99$ & $66.00-80.99$ & $\begin{array}{c}68.00-84.99 \\
(16.99)\end{array}$ \\
& $(14.99)$ & $(12.99)$ & $(12.99)$ & $(14.99)$ & $(16.99)$ \\
\multirow{2}{*}{5} & $90.00-100.00$ & $83.00-100.00$ & $83.00-100.00$ & $81.00-100.00$ & $85.00-100.00$ \\
& $(10.00)$ & $(17.00)$ & $(17.00)$ & $(19.00)$ & $(15.00)$ \\
\hline
\end{tabular}

Tablica 2: Viša razina (ljetni rok) - postotna rješivost. U zagradama je naznačena razlika za istu ocjenu.

Ove dvije tablice još će konkretnije objasniti tablica koja slijedi, a koja se odnosi na ispit iz matematike na državnoj maturi u ljetnom roku školske godine 2017./2018.

\begin{tabular}{|c||l|c|c|c|}
\hline \multirow{2}{*}{} & \multicolumn{2}{||}{ OSNOVNA RAZINA (40 bodova) } & \multicolumn{2}{|c|}{ VIŠA RAZINA (60 bodova) } \\
\cline { 2 - 5 } Ocjene & Postotna riješenost & Interval bodova & Postotna riješenost & Interval bodova \\
\hline \hline 1 & $0.00-24.99$ & $0.00-9.99$ & $0.00-24.99$ & $0.00-14.99$ \\
\hline 2 & $25.00-46.99$ & $10.00-18.79(8.79)$ & $25.00-45.99$ & $15.00-27.59(12.59)$ \\
\hline 3 & $47.00-66.99$ & $18.80-26.79(7.99)$ & $46.00-67.99$ & $27.60-40.79(13.19)$ \\
\hline 4 & $67.00-84.99$ & $26.80-33.99(7.19)$ & $68.00-84.99$ & $40.80-50.99(10.19)$ \\
\hline 5 & $85.00-100.00$ & $34.00-40.00(6.00)$ & $85.00-100.00$ & $51.00-60.00(9.00)$ \\
\hline
\end{tabular}

Tablica 3: Ispit iz matematike na državnoj maturi u ljetnom roku školske godine 2017./2018. Ispit na osnovnoj razini je imao 40 zadataka, a na višoj 49 .

Apsurdno je da, na primjer, u osnovnoj razini učenik s 10 riješenih zadataka ima ocjenu dovoljan kao i učenik s 19 riješenih zadataka. Ova činjenica provocira vrlo koristan prijedlog, da se pored ocjene evidentira i postotna rješivost. Nije ista ocjena dovoljan s ostvarenih $25.00 \%$ i ona s ostvarenih $46.99 \%$. Pametnome dosta.

\section{$4 \quad$ Konac djelo uvijek ne krasi}

Čitatelj treba da svoju pozornost usmjeriti na ocjene ostvarene na ispitu iz matematike na državnoj maturi školske godine 2017./2018. (ljetni 


\begin{tabular}{|l||c|c|c|c|c|}
\hline Razina/ocjena & 1 & 2 & 3 & 4 & 5 \\
\hline \hline Osnovna razina & 3146 & 6967 & 5366 & 2976 & 1252 \\
\hline Viša razina & 1277 & 4057 & 3214 & 1369 & 711 \\
\hline \multirow{2}{*}{ Osnovna i viša razina } & $\begin{array}{c}4423 \\
(15 \%)\end{array}$ & $\begin{array}{c}11024 \\
(36 \%)\end{array}$ & $\begin{array}{c}8580 \\
(28 \%)\end{array}$ & $\begin{array}{c}4345 \\
(14 \%)\end{array}$ & $\begin{array}{c}1963 \\
(6 \%)\end{array}$ \\
\hline
\end{tabular}

Tablica 4

rok), tablica 4 .

Zaključak: Rezultati - slabi ili vrlo slabi. Od 30335 ocjena (učenika), nedovoljnih i dovoljnih ocjena ukupno je 15447 (51\%), a vrlo dobrih i odličnih samo $\mathbf{6 3 0 8}(21 \%)$ čime se vrlo teško pomiriti, posebno zbog činjenice što je prag za dobivanje pozitivne ocjene na osnovnoj i višoj razini bio $25 \%$ ostvarenih bodova. Pragovi su bili i ostali niski. Svemu tome treba dodati da su na spomenutoj državnoj maturi na ispitu iz matematike na obje razine (školske godine 2017./2018.) zadatci bili relativno lako rješivi.

\section{Prijedlozi :}

1. Eliminirati ispite na osnovnoj razini. Učenike ispitivati jedinstvenim ispitom - jednak ispit za sve.

2. Uz ocjenu obvezno naznačiti i postotnu rješivost ispita.

3. Prema Zakonu o osnovnoj i srednjoj školi osnažiti u školama dopunsku nastavu (rad s učenicima koji iz objektivnih razloga teže usvajaju programski sadržaj matematike) i dodatnu nastavu (rad s darovitim učenicima i učenicima koji pokazuju poseban interes za matematiku), čime bi se dobrim dijelom izbjegle instrukcije na koje roditelji troše veliki novac, a čija je kvaliteta često upitna.

4. Nakon državne mature objaviti uspješnost učenika po školama (nema razloga da se ne istakne dobre rezultate kao priznanje za dobar rad učitelja/nastavnika i učenika, ali isto tako da se druge upozori na zahtjev za poboljšanje rada).

5. Zbog inflacije vrlo visokih ocjena u osnovnoj školi $i$ indirektnog utjecaja na rezultate ispita na državnoj maturi, ponovno bi trebalo aktualizirati završni ispit iz hrvatskog jezika, stranog jezika i matematike nakon završene osnovne škole, tzv. „malu maturu”. 


\section{Literatura}

[1] Nacionalni centar za vanjsko vrednovanje obrazovanja: https://www.ncvvo.hr

Vinko Bajrović

umirovljeni viši školski savjetnik za matematiku

E-mail adresa: vinko.bajrovic@st.t-com.hr 